\title{
Empirical Software Proposal for The Simulation and Optimization of The Galvanizing Process by Thermal Diffusion
}

\author{
Víctor García* and Raúl Nimo \\ Facultad de Ciencias, Campus Universitario Río San Pedro, Spain \\ Received: 垩 June 20, 2018; Published: 䟧July 18, 2018
}

*Corresponding author: Víctor García, Facultad de Ciencias, Campus Universitario Río San Pedro, Universidad de Cádiz, 11510 Puerto Real, Cádiz, Spain, Tel: +34-956872292; Email: victorjesus.garcia@uca.es

\begin{abstract}
The galvanizing process by thermal diffusion or Sherardizing is a process used by the industry to increase the corrosion resistance of some metals, especially steel. However, achieving a good optimization of this process, that is, an optimal consumption of Zn dust without exceeding the necessary quantity needed to get a homogenous coating layer thick enough to provide an efficient anti-corrosive property is not always easy. This work explores the difficulties found in the industry to optimize that process, and we propose a software that allow simulating and considering different parameters to propose the quantity of $\mathrm{Zn}$ dust to be used depending on the working conditions, the parts to by coated and the container used. This software allows also considering, in the simulation, the addition of $\mathrm{Zn}$ halides for improving the coating process.
\end{abstract}

Keywords: Sherardizing; Coating Software; Thermal Diffusion; Galvanized Steel

\section{Introduction}

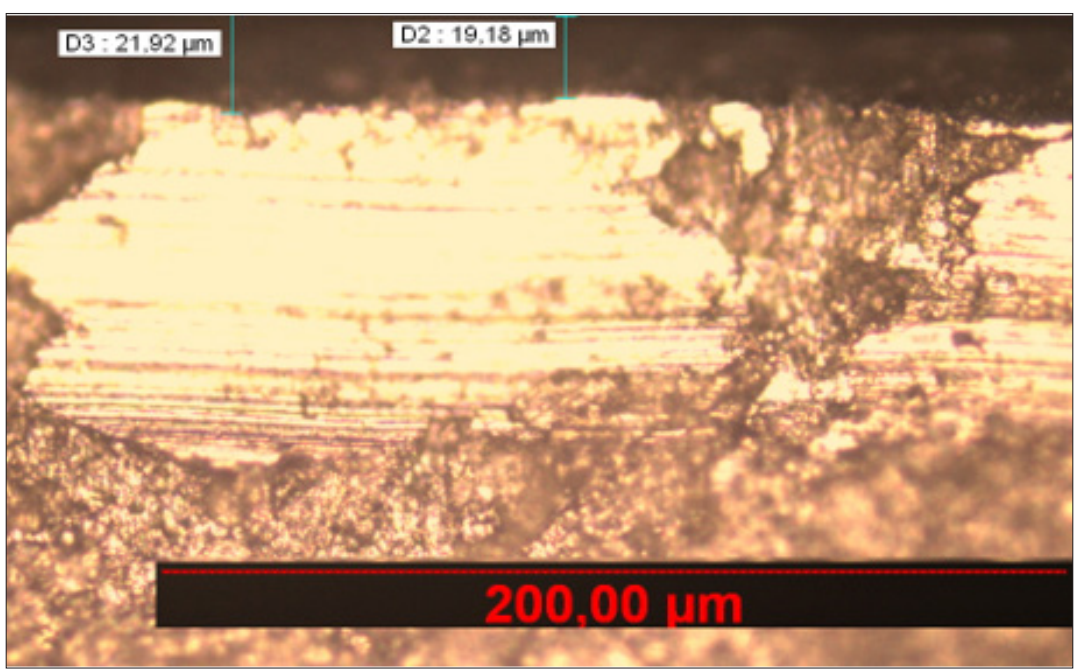

Figure 1: Profile of an example galvanized part, shown the Zn layer on the top.

Zinc coatings is a method to brings great advantages in the protections of ferrous substrates [1-2]. There are different methods to perform $\mathrm{Zn}$ coatings [3], but the Sherardizing process is a thermochemical process very promising from the environmental point of view [4-5]. Although, its production efficiency is lower than other methods. In this process, the parts are gushed with $\mathrm{Zn}$ dust, generally in a revolving drum heated at temperatures between $320^{\circ} \mathrm{C}$ and $420^{\circ} \mathrm{C}$, keeping the temperature under the $\mathrm{Zn}$ melting point. As a result, $\mathrm{Zn}$ vapor is formed that diffuses in the steel surface forming a coating alloy of Fe-Zn of between 10 to $75 \mu \mathrm{m}$, (Figure 1) depending on the working conditions (mainly the working temperature and the annealing time). Due to the working temperature for the Sherardizing, all expected intermetallic phases are formed during this process, as can be seen 
in the Fe-Zn diagram of Kubaschewski [6] see Figure 2. Therefore, the numerical simulation of those phases formation is not an easy work, and even the most actual software has to perform several kind of assumptions to be able of simulating the growing of the different phases [7]. However, it is not the aim of this work. In the present paper, we do an empirical study of several Sherardizing processes being performed in the industry to allow us proposing the best working conditions and optimize the quantity of Zn dust to use in each particular case. In addition, a simple software has been created to manage the relations found in this work and be easily applicable by any user.

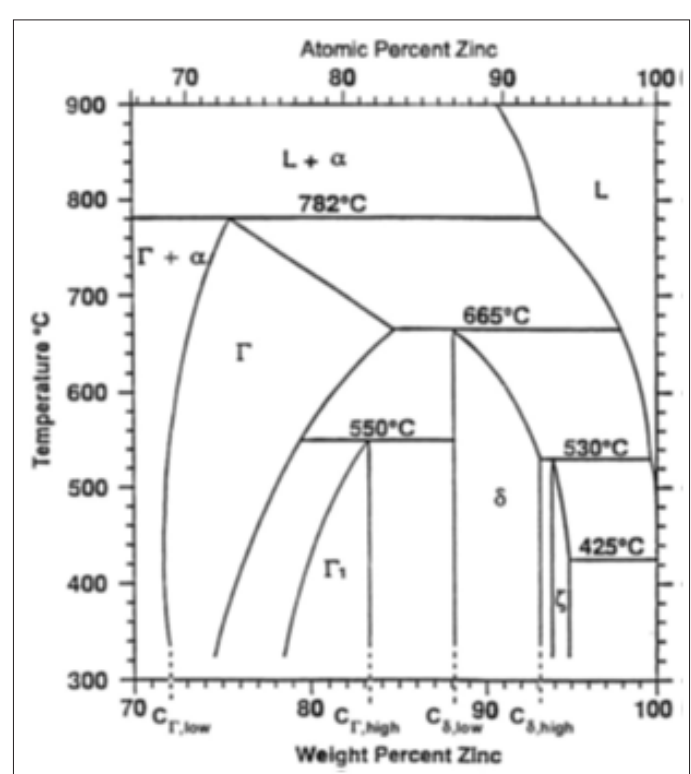

Figure 2: Zinc-rich part of the Fe-Zn phase diagram [6].

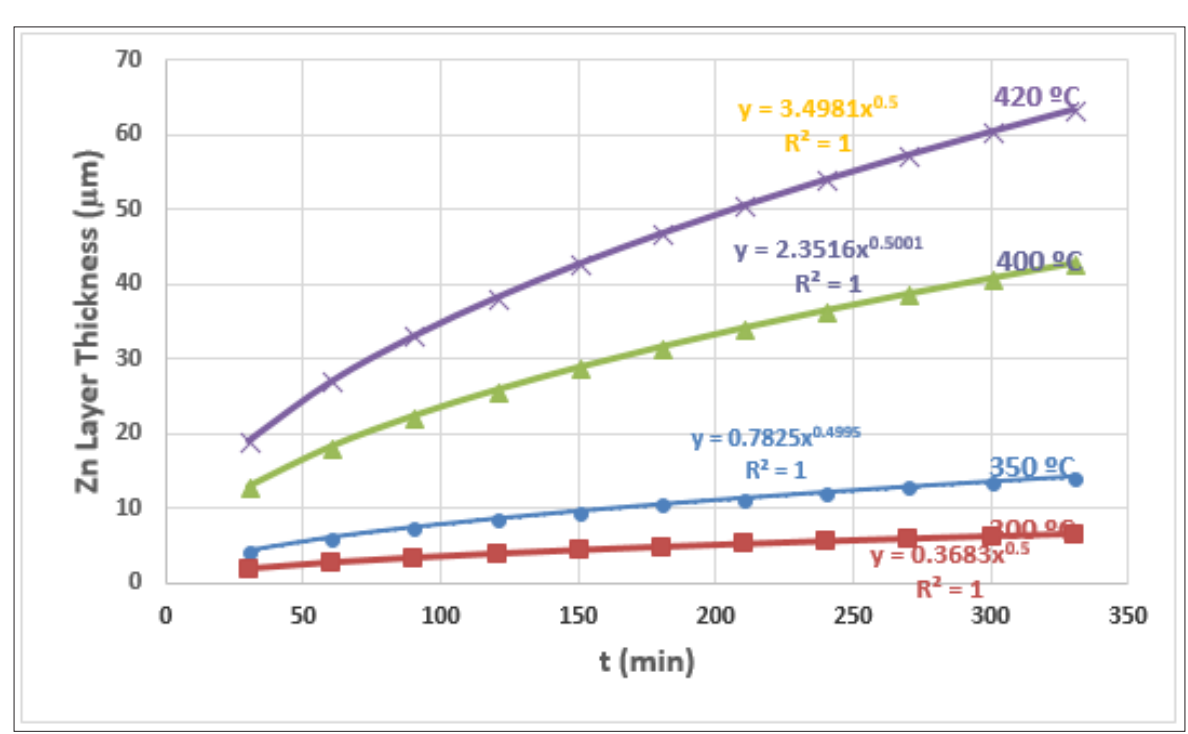

Figure 3: Zn layer thickness $(\mu \mathrm{m})$ versus the annealing time (min).

\section{Methodology}

During a year, data of working conditions and results of the galvanizing process were collected from different industrial drums and working conditions. Although, the galvanized parts studied in this work were of different shapes, we selected those having similar chemical composition, as described in the Table 1 . The $\mathrm{Zn}$ dust used have a composition of $91 \% \mathrm{Zn}$ and $9 \% \mathrm{Al}$. Some results achieved during the collection of data can be seen in Figure 3 where the thickness of the Zn layer was obtained by X-Ray Fisherscope 4000 equipment regarding the annealing time for different working temperatures. In this figure, it can be seen that the data achieved are in agreement with the equation (1) of the empiric growth law [8-9].

$$
\Delta l=K \cdot t^{n}
$$


Table 1: Composition range wt.\% of the parts studied in this work.

\begin{tabular}{|c|c|c|c|c|c|c|}
\hline & C & Al & Si & P & S & Mn \\
\hline Steel alloy & $0.041-0.055$ & $0.039-0.047$ & $0.1830-0.1940$ & $0.0182-0.0190$ & $0.013-0.015$ & $0.225-0.273$ \\
\hline
\end{tabular}

Where K represents the growth-rate constant and $\mathrm{n}$ the growth-rate time constant.

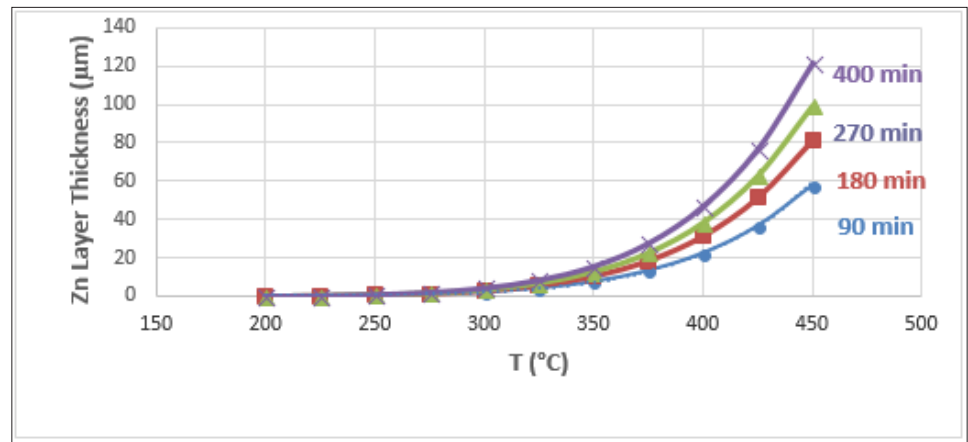

Figure 4: $\mathrm{Zn}$ layer thickness $(\mu \mathrm{m})$ versus the working temperature $\left({ }^{\circ} \mathrm{C}\right)$.

And Figure 4 shows the representation of Zn layer thickness regarding the working temperature. Therefore, in order to optimize the Sherardizing process from the industrial point of view (minimal energy and Zn consumption), we need to know the sources available to play with these two parameters, but they are not the only one, in order to determine the optimized quantity of $\mathrm{Zn}$ to be employed for achieving the specified layer thickness on the parts to be galvanized, we have to take in consideration two consuming Zn points:

a) Working atmosphere: the gases $\mathrm{O}_{2}, \mathrm{H}_{2}$ and $\mathrm{CO}_{2}$ in the containing drum are $\mathrm{Zn}$ consumers, especially at the working temperature.

b) The interior total surface of the containing drum: The walls of the container also consume certain quantity of $\mathrm{Zn}$ during the process.

In order to consider and select all these parameters for a better optimized process, we have created a simple software that indicates the working conditions to achieve the desired/specified
Zn layer thickness as well as the optimized quantity of $\mathrm{Zn}$ to be used considering the efficiency lost indicated above. For considering the first point (working atmosphere \% of Zn consumer gases), it is done through the free volume left on the drum, an initial proposal for these percentages is stablished in the software, but it can be modified by the user.

For the second point (Zn consumption by the revolving drum), after studying the data collected from the most common kind of industrial thermal drums, an empirical constant was achieved to estimate the $\mathrm{Zn}$ consumption regarding a clean and homogenous drum total surface area according to the next relation:

$$
W Z n=1.98 \cdot E-3\left(\mathrm{Kg} / \mathrm{m}^{2}\right) \cdot S
$$

Where WZn is the Kg of Zn dust consumed by the drum and $\mathrm{S}$ is the inner total surface of the drum.

In addition, the proposed software also allows to take into consideration the improvement of the efficiency of the Sherardizing process when zinc halides are added pointed out in [10].

\section{Results}

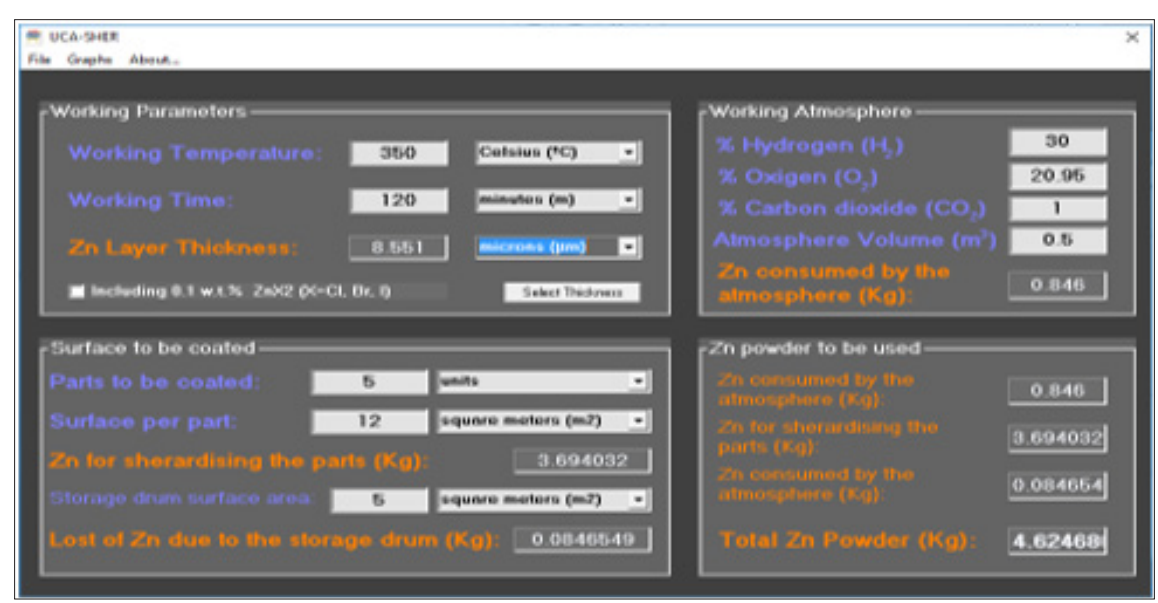

Figure 5: Main screen of the software UCA-SHER. 
As a result, we achieved the software called UCA-SHER to take into consideration all the parameters treated in this work, and that can be downloaded at [11] (Figure 5). By clicking the button "Select Thickness" we can select the wished $\mathrm{Zn}$ thickness to achieve in the parts by including one of the two parameters:
a) The working temperature or
b) The annealing time see Figure 6.

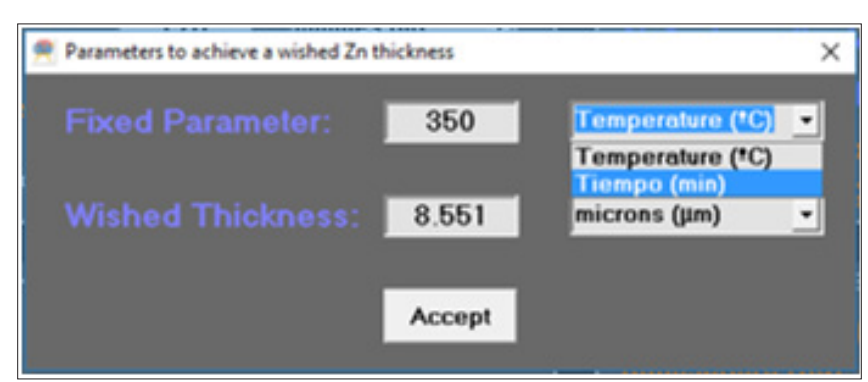

Figure 6: Whished $\mathrm{Zn}$ thickness selection to determine the working parameters.

Also, by clicking on the "Graphs" option in the menu bar of this software, we can select different kind of plots: Thickness/ Temperature or Thickness/Annealing time, by indicating the annealing time and temperature range in the first option or the working temperature and the annealing time range in the second option. In addition, if we select the Thickness/Annealing time, a least square regression is automatically performed to the relation empirically achieved, achieving the corresponding power formula in agreement with [1]. But also, we can apply the improving process indicated in [10], to check the improvement achieved by adding a $0.1 \%$ w.t. of $\mathrm{Zn}$ halides (Figure 7). For the 9 cases studied, by using the proposed software taking into account all the concerning parameters/relations found affecting the galvanizing process from an industrial point of view, we were able to reduce an average of $12 \%$ of the exceed $\mathrm{Zn}$ quantity and a $7 \%$ the energy consumption for the thermal drums due to a wrongly manage of the working parameters by the industrial sector.

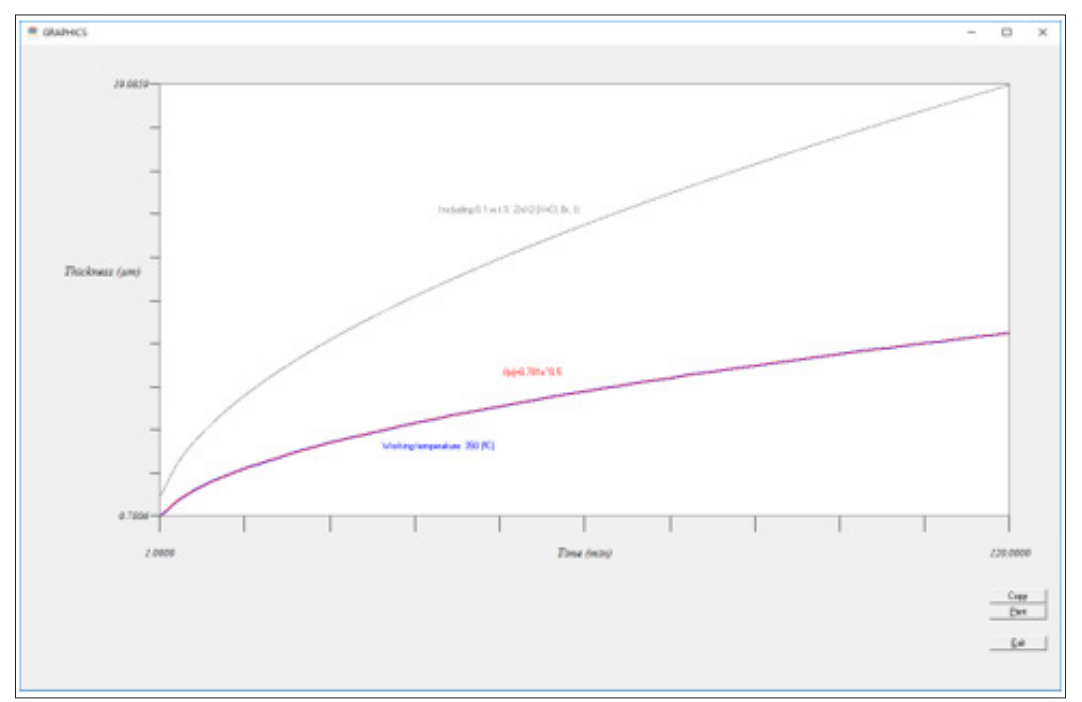

Figure 7: Graph option of the UCA-SHER software, showing the improvement of the Sherardizing process when Zn halides are added.

\section{Conclusion}

a) The industrial sector, in general, does not correctly manage the working parameters for the Sherardizing process, making a non-efficient use of the resources (Zn dust and Energy).

b) In order to optimize the thermal diffusion process for the industrial point of view all the parameters: annealing time, working temperature, working atmosphere and the surface of the drum must be considered.

c) Managing the working conditions by the proposed software, the galvanizing process efficiency could be greatly improved.

\section{References}

1. Marder AR (2000) The Metallurgy of Zinc-Coated Steel Mater Sci 45(3): 191-271.

2. Culcasi PR, Sere JD, Elsner CI, Di Sarli AR (1999) Control of the Growth of Zinc-Iron Phases in the Hot-dip Galvanizing Process, Surf Coat Technol 122(1): 21-23.

3. Hamid ZA, Aal AA, Hassan HB, Shaaban (2010) A Process and performance of hot dip zinc coatings containing $\mathrm{ZnO}$ and $\mathrm{Ni}-\mathrm{P}$ under layers as barrier protection. App Surf Sci 256(13): 4166-4170.

4. Vourlias G, Pistofidis N, Chaliampalias D, Pavlidou E, Stergioudi G, et al. (2006) Zinc Deposition with Pack Cementation on Low Carbon Steel Substrates J. Alloys Compd 416(1): 125-130. 
5. Pistofidis N, Vourlias G, Chaliampalias D, Chrysafis, K, Stergioudis G, et al. (2006) EK DSC Study of the Deposition Reactions of Zinc Pack Coatings up to $550^{\circ} \mathrm{C}$. JTherm Anal Calorim 84(1): 191-194.

6. Kubaschewski O (1982) Iron-Binary Phase Diagrams. Springer Verlag, Berlin, Heidelberg, Germany.

7. Gao H, Xiaobo Li, Wenying F, Peng D (2018) Numerical Modeling of Zinc Diffusion During Sherardizing Process. J Phase Equilib Diffus 39(2): 237 245.

\section{ISSN: 2574-1241}

DOI: $10.26717 / B J S T R .2018 .07 .001430$

Víctor García. Biomed J Sci \& Tech Res

This work is licensed under Creative Commons Attribution 4.0 License

Submission Link: https://biomedres.us/submit-manuscript.php
8. Marder AR (2000) The Metallurgy of Zinc-Coated Steel. Progress in Materials Science 45(3): 191-271.

9. Mackowiak J, Short NR (1979) Metallurgy of galvanized coatings. Mater 24(1): 1-19.

10. Wortelen D, Frieling R, Bracht H, Graf W, Natrup F (2015) Impact of zinc halide addition on the growth of zinc-rich layers generated by sherardizing. Surf \& Coat Tech 263: 66-77.

11. García V Nimo R, UCA-SHER. 